\title{
Fractional Extraction, Isolation and Identification of Biologically Active Compounds from Anamirta cocculus (L.) Wight \& Arn to Control Culex quinquefasciatus Say and Aedes albopictus Skuse
}

\author{
Anju Viswan K', E Pushapalatha ${ }^{2}$, SArivudainambi ${ }^{3}$, TSelvamuthukumaran ${ }^{4}$ \\ 1,2Biopesticides \& Toxicology Laboratory, Department of Zoology, University of Calicut, Malappuram, Kerala, India. \\ ${ }^{3,4}$ Department of Entomology, Faculty of Agriculture, Annamalai University, Chidambaram, Tamil Nadu, India. \\ DOI: https://doi.org/10.24321/0019.5138.202031
}

\section{I $\quad \mathbf{N} \quad \mathbf{F} \quad \mathbf{O}$}

\section{Corresponding Author:}

Anju Viswan K, Department of Zoology, University of Calicut, Malappuram, Kerala, India.

E-mail Id:

anjuviswan@gmail.com

Orcid Id:

https://orcid.org/0000-0001-7926-5826

How to cite this article:

Anju Viswan K, Pushapalatha E, Arivudainambi $\mathrm{S}$, Selvamuthukumaran T. Fractional Extraction, Isolation and Identification of Biologically Active Compounds from Anamirta cocculus (L.) Wight \& Arn to Control Culex quinquefasciatus Say and Aedes albopictus Skuse. J Commun Dis 2020; 52(3): 53-57.

Date of Submission: 2020-03-12

Date of Acceptance: 2020-05-16

\section{$\begin{array}{llllllll}\mathbf{A} & \mathbf{B} & \mathbf{S} & \mathbf{T} & \mathbf{R} & \mathbf{A} & \mathbf{C} & \mathbf{T}\end{array}$}

Background \& Objectives: Development of resistance towards synthetic insecticides is one of the major problems in vector control programmes and it can be reduced to an extent by the alternate use of botanical or bio insecticides. The present study aims to find out the larvicidal activities of Anamirta cocculus (L.) Wight and Arn against Culex quinqueafsciatus Say and Aedes albopictus Skuse and to isolate the most active compounds present in the active fraction of the plant extract.

Methods: Cold extracts of $A$. cocculus seeds were taken using methanol as solvent and fractionation was done using the solvents $n$-hexane, ethyl acetate and acetone by column chromatographic method. Bioassays were conducted using all these extracts and $\mathrm{LC}_{50}$ were calculated using the probit analysis developed by Finney. The structural elucidation of the compounds of most active fraction isolated from chromatographic studies after bioassay was done by Liquid chromatography-mass spectrometry (LCMS) and Nuclear magnetic resonance (NMR) spectroscopy.

Result: A. cocculus treated larvae exhibited more restlessness, convulsions and sluggishness, and the restless activity is more in $A e$. albopictus than in $C x$. quinquefasciatus. The activity of column fractions of $A$. cocculus was in the order Hexane $(H)>$ Acetone $(A)>H$ :EA $(3: 1)$ $>\mathrm{H}: \mathrm{EA}(2: 1)>\mathrm{H}: \mathrm{EA}(1: 1)$ : Ethyl acetate (EA): H:EA (1:2) >H:EA (1:3). The compounds present in the most active fractions were Picrotin and Menispermine respectively.

Interpretation \& Conclusion: From the results it has been proved that the plant is having potential larvicidal activity.

Keywords: Anamirta Cocculus, Aedes albopictus, Culex quinquefasciatus, Larvicidal Activity, NMR, LCMS 


\section{Introduction}

The pharmacological and insecticidal properties of herbs have been well established by researchers all around the world, especially in India where the climate is highly conducive for such pesticidal plants. Utilization of plant derived products in the management of insect pests/ vectors are not a new concept but renewed recent past due to the development of wide resistance of pests against chemical/ synthetic insecticides. The ill effects of synthetic insecticides could be reduced to an extent by the use of botanical insecticides. ${ }^{1}$

Plants are the reservoirs of complex phyto-chemicals like alkaloids, flavonoid, saponins and tannins, which are known to possess medicinal and pesticide properties. ${ }^{2}$ The plant derived metabolites, such as saponine, steroids, isoflavonoids, essential oils, alkaloids and tannins were proved as potent mosquito larvicidal compounds by many researchers in their earlier studies. In addition to natural secondary metabolites, synthetic derivatives also provide alternative source for the management of mosquitoes. ${ }^{3}$ Bioactive organic compounds exerted by plants have a complex mode of action such as growth and oviposition inhibitory, repellent activity, toxic and deterrence. ${ }^{4,5}$

In this study, Anamirta cocculus (L.) Wight and Arn., was tested for its efficacy against Aedes albopictus Skuse and Culex quinquefasciatus Say. A. cocculus is large woody climbing shrub with vertically furrowed ash coloured bark and glabrous young parts. Leaves large, simple, alternate, long petiole, petioles thickened at the base and apex broadly ovate, subcoriaceous, cordate or truncate at the base, tufts of hairs in the axils of the nerves except the basal ones, flowers greenish in long panicles, drooping from the nodes of the old wood, fruits druped kidney shaped turning red on ripening.

\section{Materials and Methods}

\section{Test Organism}

The mosquito species Aedes albopictus Skuse and Culex quinquefasciatus Say were used for the study.

\section{Plant Used in the Study}

Anamirta cocculus (L.) Wight and Arn. (Family: Menispermaceae).

\section{Cold Extraction Method}

Powder of $A$. cocculus packed as $20 \mathrm{~g}$ packets using Whatman No. 40 filter paper and held by stapler pin. The thimbles were placed carefully in to one litre conical flask thus leaving three packets per flask. Five such conical flasks were kept. Then methanol added to conical flask in such a way that the packets were submerged in the solvent. The mouth of the conical flasks was tightly plugged with non-absorbent cotton, wrapped with aluminium foil and paraffin wax paper and secured using rubber band. Whenever needed methanol was added to the content. After 48 hours, the extracts obtained from the conical flasks were filtered through Whatman No. 40 filter paper. Then the collected extracts were reduced in Vacuum rotary evaporator and collected miscella were transferred to amber coloured bottle, tightly covered, labelled and stored in a deep freezer at $-20^{\circ} \mathrm{C}$.

\section{Fractionation of $A$. cocculus Extracts}

Fractionation of miscella was done by following column chromatography techniques. A glass column of $50 \mathrm{~cm}$ length was used. Silica gel powder (60/ 120 mesh) was packed in the column and loaded with $5 \mathrm{~g}$ of miscella. Then the miscella was eluted with different solvents (HPLC grades) and solvent systems such as n-heaxane, EA and acetone and combination of solvents at different ratio viz., n-hexane, EA, hexane: EA (1:1), hexane: EA (1:2), hexane: EA (1:3), hexane: EA (3:1), hexane: EA (2:1) and acetone.

\section{Bioassay}

Conducted using the protocol of WHO (1981). ${ }^{6} \mathrm{LC}_{50}$ were calculated using a Probit programme developed by Finney (1971). ${ }^{7}$

\section{Identification of Compounds}

The structural elucidation of the compounds isolated from chromatographic studies done by LCMS and NMR spectroscopy.

\section{Result}

The different column fractions of $A$. cocculus eluted using column chromatographic techniques were tested against III instar larvae of Cx. quinquefasciatus and Ae. albopictus (tables 1 \& 2). The data on $24 \mathrm{~h} \mathrm{LC} \mathrm{LC}_{50}$ (ppm) of the eight different fractions of $A$. cocculus tested against III instar larvae of $C_{x}$. quinquefasciatus were provided in the table 2. The $24 \mathrm{~h} \mathrm{LC}_{50}$ values ranged from $10.1 \mathrm{ppm}$ to 28.86 ppm for the different column fractions viz; hexane, EA, hexane : EA (3:1), hexane : EA (2:1), hexane : EA (1:1), hexane : EA (1:2), hexane : EA (1:3) and acetone. $24 \mathrm{hr}$ $\mathrm{LC}_{50}$ and $\mathrm{LC}_{90}(\mathrm{ppm})$ values obtained after the treatment of the eight column fractions of $A$. cocculus with III instar of Ae. albopictus is provided in table 3. As in the case of $C x$. quinquefasciatus the activity of $A$. cocculus was same as that for Ae. albopictus. The $24 \mathrm{~h} \mathrm{LC}_{50}$ values for the different column fractions ranged between $9.81 \mathrm{ppm}$ and $24.22 \mathrm{ppm}$ for all the eight column fractions.

\section{NMR and LCMS Analysis}

The hexane fraction of $A$. cocculus shown more activity against III instar larvae of both Ae. albopictus and $C x$. quinquefasciatus. This fraction was subjected to NMR and LCMS analyzes. 


\section{LCMS and NMR Data of A. cocculus}

\section{Fraction I}

The fraction I was subjected to ${ }^{1} \mathrm{H}$ and ${ }^{13} \mathrm{C}$ NMR and LCMS analysis. The ${ }^{1} \mathrm{H}$ and ${ }^{13} \mathrm{C}$ NMR as well as LCMS data are given in Plate $1 \mathrm{~A}, 1 \mathrm{~B}$ and $1 \mathrm{C}$.

\section{Compound I}

It is interesting to note that the structure isolated resembles the structure of 4, 6a-dihydroxy-1a1-methyl-2-oxo-5-(prop1-en-2-yl)octahydro-1a1H-oxireno[2',3':1,2] indeno[7,1-bc] furan-6-carbo- xylic acid. International Union of Pure and Applied Chemistry (IUPAC) Name: 4, 6a-dihydroxy-1a1methyl-2-oxo-5-(prop-1-en-2-yl) octahydro-1a1H- oxireno $\left[2^{\prime}, 3^{\prime}: 1,2\right]$ indeno[7,1-bc]furan-6-carboxylic acid, Chemical Formula: $\mathrm{C}_{15} \mathrm{H}_{18} \mathrm{O}_{7}$.

${ }^{1} \mathrm{H}$ NMR (400 MHz, $\mathrm{CDCl}_{3}$ ), $\delta$ (ppm): 1.18 (s, 3H, H(31), $\mathrm{H}(32)$ and $\mathrm{H}(33) .1 .54(\mathrm{~d}, 1 \mathrm{H}, \mathrm{H}(24) \mathrm{J}=1,7 \mathrm{~Hz}) .1 .95$ (d, 1H, $\mathrm{H}(23), \mathrm{J}=1.5 \mathrm{~Hz}$ ). 1.84 (s, 3H, H(35), $\mathrm{H}(36)$ and $H(37) .2 .23$ (d, $1 \mathrm{H}, \mathrm{H}(29) \mathrm{J}=2) .2 .29$ (t, 1H, H(28) J=1.9Hz). 3.59 (s, 1H, $H(34) .5 .27$ (s, 1H, H(26). 7.20 (s, 1H, H(39) (Plate No. 1A).

$\left.{ }^{13} \mathrm{C} \mathrm{NMR} \mathrm{(100} \mathrm{MHz,} \mathrm{CDCl}\right)$ ), $\delta$ (ppm): 15.2(C15), 23.0 (C20), 30.9 (C20), 34.06 (C2), 44.4 (C10), 48.6 (C3), 51.5 (C4), 61.58 (C5), 72.3 (C1), 76.7 (C8), 77.1 (C7), 112.9 (C21), 130.0 (C19), 174.5 (C11), 179.5 (C16) (Plate No. 1B).

Mass spectra ESI [M-H] ${ }^{`} 309.13$ (Actual Mol. Wt. 310.11) (Plate No. 1C).

\section{Fraction II}

The fraction II was subjected to ${ }^{1} \mathrm{H}$ and ${ }^{13} \mathrm{C}$ NMR and LCMS analysis. The ${ }^{1} \mathrm{H}$ and ${ }^{13} \mathrm{C}$ NMR as well as LCMS data are given in Plate 2A, 2B and 2C.

\section{Compound 2}

It is interesting to note that the structure isolated resembles the structure of 11-hydroxy-1, 2, 10-trimethoxy-6, 6-dimethyl-5, 6, 6a, 7-tetrahydro-4H-dibenzo [de, g] quinolin6-ium. IUPAC Name: 11-hydroxy-1, 2, 10-trimethoxy-6, 6-dimethyl-5, 6, 6a, 7-tetrahydro-4H-dibenzo [de, g] quinolin-6-ium, Chemical Formula: $\mathrm{C}_{21} \mathrm{H}_{26} \mathrm{NO}_{4}^{+}$.

${ }^{1} \mathrm{H}$ NMR (400 MHz, $\left.\mathrm{CDCl}_{3}\right), \delta$ (ppm): 1.05 (s, 6H, H(27), $H(28), H(29), H(50), H(51), H(52) .1 .96$ (t, 2H, H(32), H(33) $\mathrm{J}=6.7 \mathrm{~Hz} .3 .11(\mathrm{~d}, 2 \mathrm{H}, \mathrm{H}(36), \mathrm{H}(37) \mathrm{J}=2.3 \mathrm{~Hz} .3 .79(\mathrm{t}, 2 \mathrm{H}$, $\mathrm{H}(30)$ and $\mathrm{H}(31) \mathrm{J}=3.5 \mathrm{~Hz} .1 .32$ (s, 9H, $\mathrm{H}(40), \mathrm{H}(41), \mathrm{H}(42)$, $H(43), H(44), H(45), H(46), H(47), H(48), H(49) .5 .27$ (t, 1H, $\mathrm{H}(35) \mathrm{J}=1.6 \mathrm{~Hz} .4 .49$ (s, 1H, H(43). $6.99-7.325$ (Ar. C-H). (Plate No. 2A).

${ }^{13} \mathrm{C} \mathrm{NMR}\left(100 \mathrm{MHz}, \mathrm{CDCl}_{3}\right.$ ), $\delta$ (ppm): 29.80(C20), 29.80(C20 and C25), 31.94 (C15), 34.0(C1 and C6), 46.7 (C12), 43.2 (C4), 50.7 (C3), 61.6 (C11), 113.0-139 (Ar.-C) (Plate No. 2B).

Mass spectra ESI [M-H] 355.21 (Actual Mol. Wt. 356.19) (Plate No. 2C).

\section{Discussion}

The $A$. cocculus treated larvae exhibited more restlessness, convulsions and sluggishness and the restless activity is more in Ae. albopictus than in Cx. quinquefasciatus. The sluggish and peculiar coiling movement in treated larvae might be due to the neuronal or muscular disturbances caused by active ingredients released by the extracts in to the water. After exposure to $A$. cocculus extracts, the larvae showed abnormal motions, tremors and convulsions followed by paralysis and finally settle at the bottom of the container. The result is in corroboration with the reports of Sagar and Seghal against Cx. quinquefasciatus. ${ }^{8}$

The column fractions of methanol extracts were taken using the column chromatography and analyzed their larvicidal activity against $3^{\text {rd }}$ instar larvae of both $C x$. quinquefasciatus and $A$ e. albopictus. The mortality rates were recorded and the $\mathrm{LC}_{50}$ values were calculated. The calculated values show that the hexane fraction of $A$. cocculus shows more activity than the other seven fractions. A slight difference is seen in the activity against $C x$. quinquefasciatus and Ae. albopictus. With all the eight fractions, Ae. albopictus showed less $\mathrm{LC}_{50}$ values for mortality as compared with $C x$. quinquefasciatus, which may be due to its breeding habit that they are living in fresh water and $C x$. quinquefasciatus mostly breeds in the polluted water.

The activity of column fractions of $A$. cocculus was in the order hexane $(\mathrm{H})>$ Acetone $(\mathrm{A})>\mathrm{H}$ :EA (3:1) >H:EA (2:1)> $\mathrm{H}: \mathrm{EA}(1: 1)$ : EA: H:EA (1:2) >H:EA (1:3). And the $\mathrm{LC}_{50}$ values against $A e$. albopictus and $C x$. quinquefasciatus were 9.81> $12.36>14.44>17.96>18.64>19.4>22.22>24.22$ and $10.1>15.12>16.84>19.96>20.44>22.4>24.98>28.86$ respectively.

The most active fraction of $A$. cocculus was further purified using 'Thin layer chromatography' and the fractions were again tested for their larvicidal activity and the most active fractions were analyzed by NMR and LCMS to elucidate the structure of compound present in the fraction.

Chromatographic techniques are used to identify fractions and help to isolate chemical constituents from the selected extract. The fractions isolated from the hexane fraction of $A$. cocculus were I and II. The selected fractions which showed potent activities were further analyzed using Liquid Chromatography-Mass Spectrometry. The fraction I produced the molecular ion signal (m/z) of 309.13 and the identified compound may be 4, 6a-dihydroxy-1a1-methyl2-oxo-5-(prop-1-en-2-yl)octahydro-1a1Hoxireno[2',3':1,2] indeno[7,1-bc]furan-6-carboxylic acid and its molecular formula is $\mathrm{C}_{15} \mathrm{H}_{18} \mathrm{O}_{7}$ (Picrotin).

The fraction II produced the molecular ion signal $(\mathrm{m} / \mathrm{z})$ of 355.21 and the identified compound may be 11-hydroxy-1, 2, 10-trimethoxy-6, 6-dimethyl-5, 6, 6a, 7-tetrahydro-4H- 
dibenzo [de, g] quinolin-6-ium with molecular formula $\mathrm{C}_{21} \mathrm{H}_{26} \mathrm{NO}_{4}^{+}$(Menispermine).

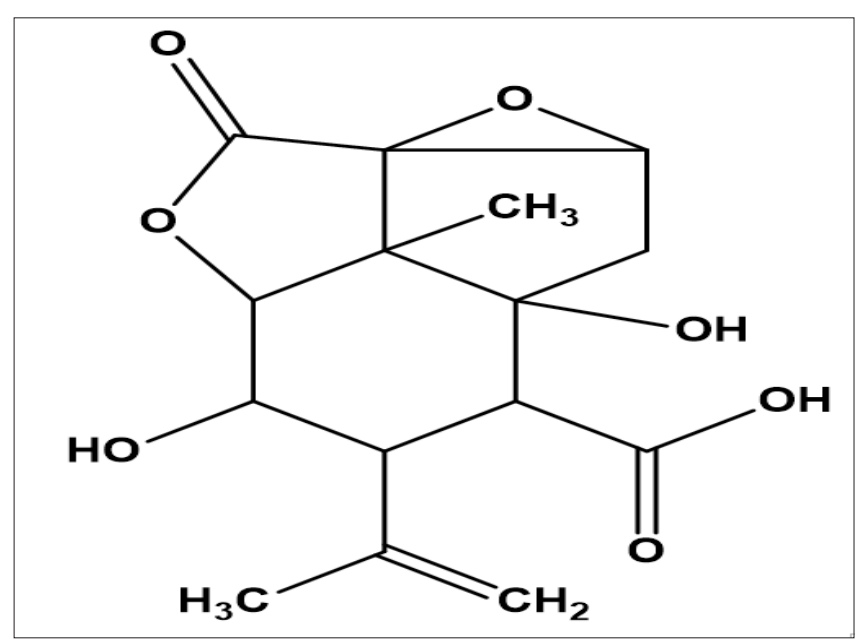

Figure I.Picrotin

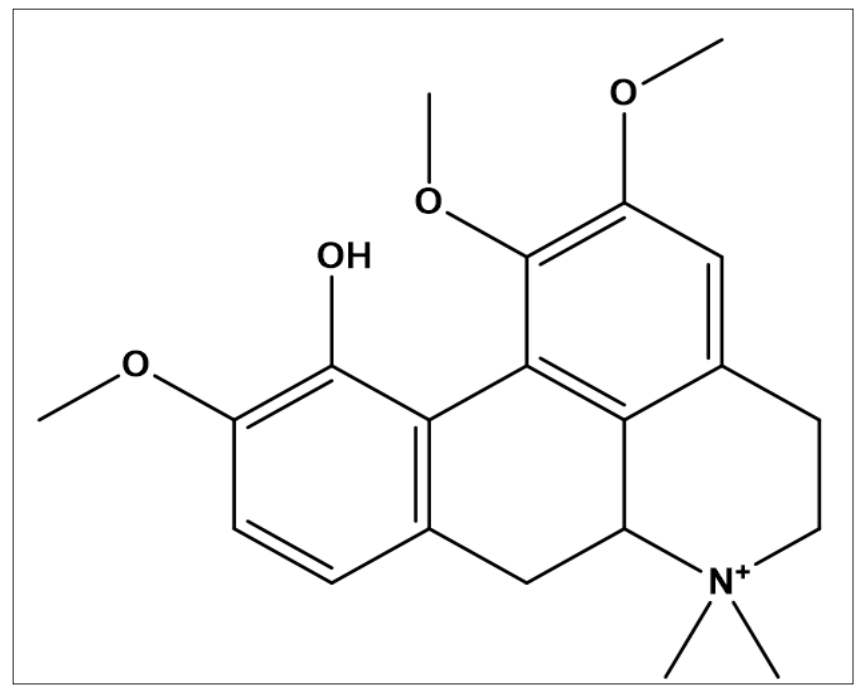

Figure 2.Menispermine

The larvicidal mechanism by the plant extracts is generally due to the presence of alkaloids. It is cytotoxic nature and causes damage of protein kinase which is involved in signal transduction and development process among most of the cells and tissues of mosquitoes. ${ }^{9,10}$ Acetone extracts of $A$. cocculus fruit showed significant reduction in fecundity and hatchability. And it also proved its larvicidal activity against different instars of $C X$. pipiens. ${ }^{11,12}$

The rich presence of fats and fatty acids in the seeds of $A$. cocculus might be rendering the extracts a waxy-solid consistency as well as an acidic nature. Due to the presence of various bioactive compounds in A. cocculus, antibacterial, antifungal and anti-inflammatory properties have been attributed to it. ${ }^{13} A$. cocculus remains a popular folk remedy in Asia and adjacent regions. Fruits of $A$. cocculus contain picrotoxin, which was also known as cocculin. Picrotoxin was a crystalline equimolar mixture of two sesquiterpene dilactones, i.e. picrotoxinin and picrotin. Furthermore, the fruits contain the isoquinoline alkaloids menispermine, paramenispermine, magnoflorine, stephorine, berberine, palmatine and I, 8- oxotetrahydropalmatine. ${ }^{14}$

From the results it has been proved that the plant is having high larvicidal activity. The insecticidal property provides a safe, easily degradable and suitable alternative to synthetic insecticides. Further purification and field performance of the active compounds are going on to find out the field activity of purified compounds.

\section{Acknowledgement}

UGC BSR for providing financial support for carry out this project.

Department of Agricultural Entomology and Department of Chemistry, Annamalai University, Tamil Nadu, for providing facilities to carry out the chromatographic, NMR and LCMS works.

\section{Conflict of Interest: None \\ References}

1. Tehri K, Singh $\mathrm{N}$. The role of botanicals as green pesticides in integrated mosquito management: $A$ review. Int J Mosq Res 2015; 2(1): 18-23.

2. Shaalan EAS, Canyonb D, Younesc MWF et al. A review of botanical phytochemicals with mosquitocidal potential. Environ Int 2005; 3: 1149-1166.

3. Shivakumar MS, Srinivasan R, Natarajan D. Larvicidal potential of some Indian medicinal plant extracts against Aedes aegypti (L.) Asian J Pharm clin Res 2013; 6(3): 77-80.

4. Ezeonu FC, Chidume GI, Udedi SC. Insecticidal properties of volatile extracts of orange peels. Bioresour Technol 2001; 76(3): 273-274.

5. Carlini CR, Grossi-De-Sá MF. Plant toxic proteins with insecticidal properties. A review on their potentialities as bioinsecticides. Toxicon 2002; 40(11): 1515-1539.

6. World Health Organization. Instruction for determining the susceptibility or resistance of mosquito larvae to insecticide. 1981. Available form: https://apps.who. int/iris/handle/10665/69615.

7. Finney DJ. Probit Analysis. Cambridge University Press, 1971.

8. Sagar SK, Sehgal SS. Toxicity of neem seed coat extract against mosquitoes. Indian J Ent 1997; 59(2): 215-223.

9. Goel G, Makkar HP, Francis G et al. Phorbol esters: structure, biological activity, and toxicity in animals. Int J Toxicol 2007; 26: 279-288.

10. Ghosh A, Chowdhury N, Chandra G. Plant extracts as potential mosquito larvicides. Indian J Med Res 2012; 135(5): 581-598.

11. Pushpalatha E, Najeeba MB, Santhini KP. Anamirta cocculus L. (Wight \& Arn), Pogostemon paniculatus 
(Wild) Benth, Culex pipiens. International Journal of Applied Biology and Pharmaceutical Technology 2014; 5(3): 159-162.

12. Pushpalatha E, Aiswarya D, Sharihan EK et al. Reproductve toxicity of Anamirta cocculus (L.) Wight and Arn and Sphagneticola trilobata (L.) Pruski extracts on Culex pipiens (L.) Diptera, Culicidae. Prospects in Bioscience: Addressing the Issues 2012; 389-392.

13. Satya V, Paridhavi M. Ethano-botanical, phytochemical and pharmacological review of Anamirta cocculus (Linn.) Wight and Arn. Int J Rev Life Sci 2012; 2(1): 1-6.

14. Jijith US, Sudhakaran Nair CR, Ajithkumar KC et al. Phytochemistry and Pharmacology of Anamirta cocculus Wild. J Pharmacogn Phytochem 2016; 8(2): 90-92. 